\title{
Penfigoide cicatrizal de largo tiempo de evolución
}

\author{
Moya Villaescusa MJ*, Saura Pérez M**, López Jornet P***
}

\section{RESUMEN}

Introducción: El penfigoide cicatrizal es una enfermedad autoinmune, inflamatoria crónica, ampollar, de carácter benigno, que afecta principalmente a membranas mucosas.

Objetivo: El objetivo de este artículo es mostrar el seguimiento de los cambios locales (dentales y mucosos) y sistémicos ocurridos durante un periodo de 15 años en una paciente con penfigoide cicatrizal.

Caso clínico: Mujer de 65 años de edad, con hipertensión arterial controlada mediante fármacos, sin otros antecedentes de interés. No alergias conocidas ni hábitos tóxicos. Presenta lesiones erosivas y ampollares en encías, paladar y mucosas yugales, sin afectación de otras mucosas o piel. Actualmente se encuentra en periodo de rehabilitación protésica.

Discusión. Se discuten los tratamientos llevados a cabo, grado de cumplimento, así como las complicaciones que han ido apareciendo.

Palabras clave: Penfigoide cicatrizal, penfigoide membrana mucosa, penfigoide ocular, penfigoide benigno.

\section{SUMMARY}

Introduction: The cicatrizal pemphigoid is a chronic inflammatory autoimmune disease, subepithelial blistering disorder, benign, that affects mainly to mucous membranes.

Objective: The main aim of this article is to show the pursuit of the local (dental and mucous) and systemic changes that have happened for 15 year in a patient who suffers from cicatrizal pemphigoid.

Clinical case: We report the case of a 65 year old woman, with arterial hypertension controlled by medicines, with no other interesting medical record. There are neither any known allergies nor any toxic habits. She suffers from erosive and blister lesions in gums, palate and cheek mucous, without any affectation on other mucous or skin. At present she's in a period of prothetic rehabilitation.

Discussion. 15 year-old treatments on this patient are going to be discussed and analysed in this article, both their level of fulfilment and the complications that have been appearing.

Key words: Cicatrizal pemphigoid, mucous pemphigoid membrane, ocular pemphigoid, benign pemphigoid.

* Licenciada en Odontología. Curso de especialista Universitario en Gerodontología. Facultad de Medicina y Odontología. Universidad de Murcia.

** Profesor Asociado de Periodoncia. Facultad de Medicina y Odontología. Universidad de Murcia.

*** Profesora titular de Medicina Bucal. Facultad de Medicina y Odontología. Universidad de Murcia.

Moya Villaescusa MJ, Saura Pérez M, López Jornet P. Penfigoide cicatrizal de largo tiempo de evolución. Av. Odontoestomatol 2003; 19-4: 167-175 


\section{INTRODUCCIÓN}

En el primer simposium internacional sobre el penfigoide cicatrizal (PC) celebrado en Chicago por distintos grupos de especialistas se dieron unas directrices a seguir para identificar y tratar esta entidad; definiéndose como una enfermedad autoinmune, inflamatoria crónica, de carácter benigno, que evoluciona de forma lenta, progresiva, a brotes, con periodos de remisión y exacerbación espontáneos ${ }^{(1)}$.

Su localización predominantemente es en mucosa oral (83-100\% de los casos) ${ }^{(2)}$, aunque también pueden afectarse otras zonas como la conjuntiva del ojo, la laringe, los genitales, el esófago y la piel. Afecta a la unión epitelioconectiva y cursa con la formación de ampollas subepiteliales. Se caracteriza por un depósito de inmunoglobulina G (Ig G), inmunoglobulina $\mathrm{A}(\lg \mathrm{A})$ y factor $\mathrm{C} 3$ del complemento a lo largo de la membrana basal del epitelio ${ }^{(1-8)}$.

Es de incidencia reducida y la edad predominante de aparición suele ser entre los 40 y los 80 años (rara en niños), con un predominio de afectación en mujeres $1: 1.5$ hasta $1: 4$, sin predilección racial ni geográfi$\mathrm{ca}^{(2)}$.

Ha recibido distintas denominaciones: penfigoide benigno de las mucosas, penfigoide ocular, dermatitis muco sinequiante de Lortat-Jacob, penfigoide benigno ocular de Lever, membrana mucosa penfigoide...

El objetivo de este artículo es el estudio en el tiempo del penfigoide cicatrizal. Mostraremos un caso clínico de PC de 15 años de evolución, así como los cambios locales (dentales y mucosos) y sistémicos ocurridos durante este periodo.

\section{CASO CLÍNICO}

\section{Anamnesis:}

Mujer de 50 de edad acude en el año 87 al servicio de Estomatología de la Universidad de Murcia por presentar molestias en las encías y paladar desde hacía ya 3 años. No toleraba los alimentos ácidos ni

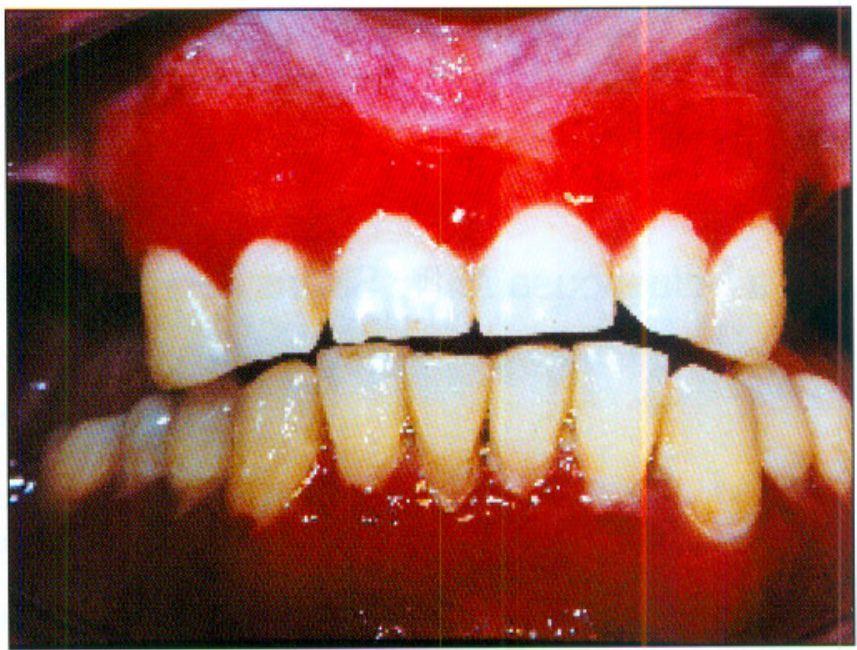

Fig. 1. Gingivitis eritematosa descamativa.

picantes. Tampoco recordaba antecedentes familiares con este tipo de problema y entre sus antecedentes personales destacaban: hernia de hiato, úlcera gástrica, artrosis cervical y un legrado uterino, sin existir alergias conocidas o hábitos tóxicos.

Los tratamientos que había recibido para su problema eran enjuagues con oraldine ${ }^{\circledast}$, aplicaciones tópicas con betadine ${ }^{\circledR}$, yodo-cortisona ${ }^{\circledR}$, Bristaciclina ${ }^{\star}$, dental y Rhodogil ${ }^{\circledR}$; no mejorando con ninguno de ellos, e incluso le realizaron varias extracciones dentarias creyendo que así mejoraría de su problema.

\section{Exploración oral:}

Localización y características de las lesiones:

- Gingivitis eritematosa descamativa que abarcaba las regiones del 17 al 27 y del 35 al 46, tanto en encía libre como adherida (Fig. 1)

- Epitelio que se descamaba fácilmente. Se podía arrancar con facilidad el epitelio intacto contiguo a las erosiones, lo que dejaba un sustrato denudado y sangrante.

- Mucosa yugal derecha: En el tercio posterior aparecía una lesión ampollar de aproximadamente $3 \times 1$ $\mathrm{mm}$. de tamaño, con base eritematosa y morfología alargada e irregular.

- Paladar duro: Gran lesión ampollar de 3 x $2 \mathrm{~cm}$. de tamaño en la zona central del paladar duro junto con otras lesiones ampollares de menor tamaño, 


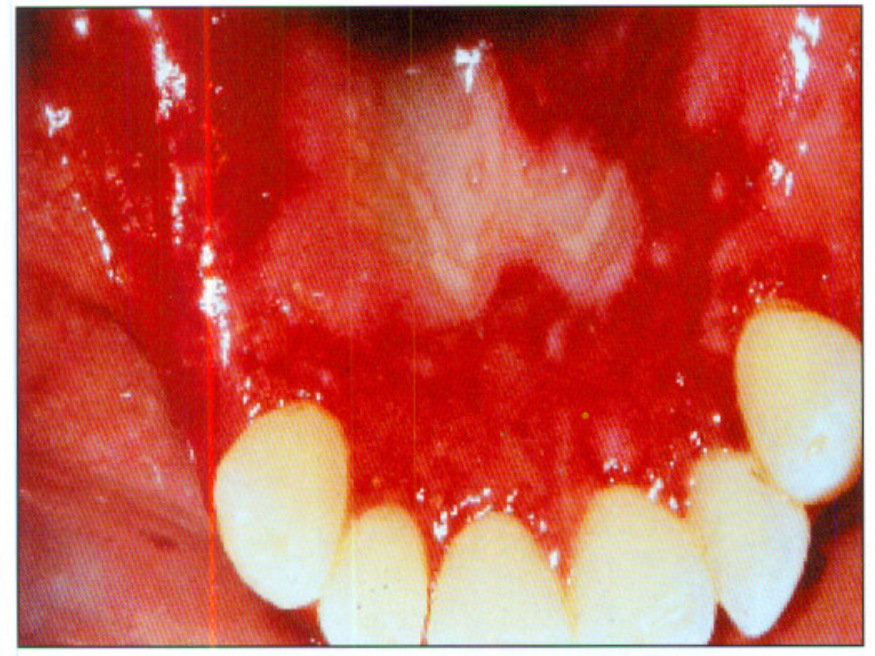

Fig. 2. Lesiones ampollares de base eritematosa.

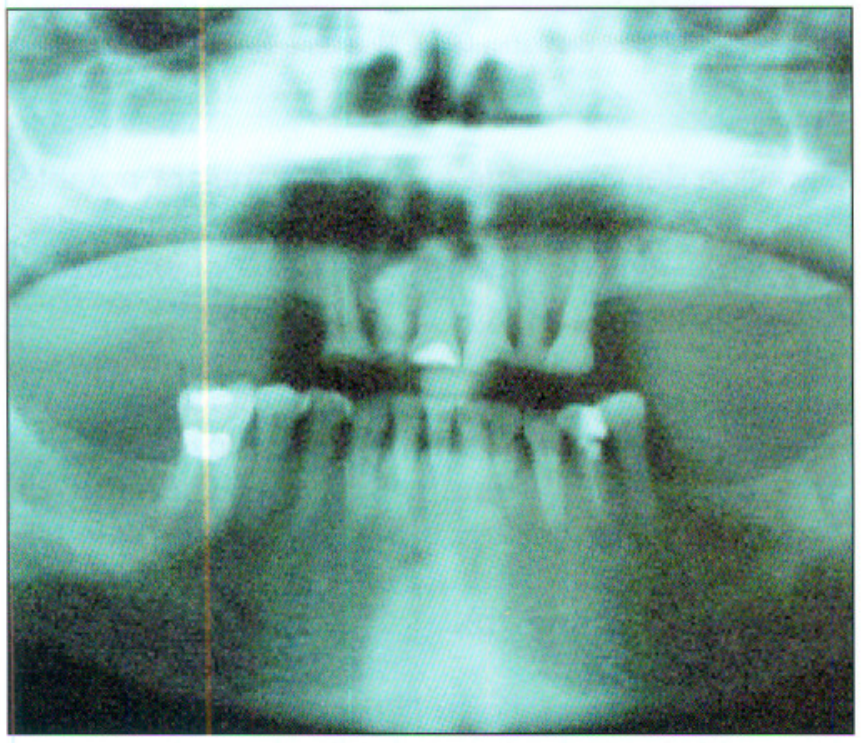

Fig. 3. Ortopantomografía. Se aprecian las ausencias dentarias y lesión radiolúcida en ápice del 34 .

$0.5 \times 0.5 \mathrm{~mm}$ de diámetro, todas ellas de base eritematosa (Fig. 2).

\section{Examen odontológico:}

Ausencia del 18 al 14, del 24 al 28, del 38 al 36, del 48 y del 47 ; sin caries ni enfermedad periodontal.

\section{Exámenes complementarios:}

1. Ortopantomografía (Fig. 3): Se observa la ausencia de las piezas dentarias anteriormente mencio-

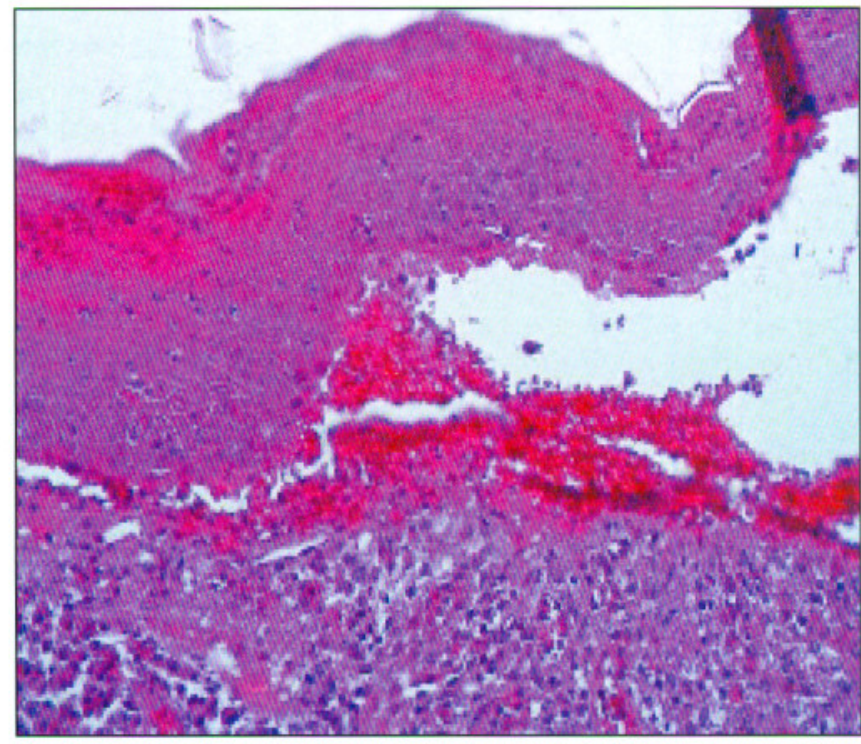

Fig. 4. Ampolla subepitelial. Obsérvese el tejido conjuntivo con un infiltrado inflamatorio crónico inespecífico con algún eosinófilo, pero con ausencia de acantólisis.

nadas y una lesión radiolúcida en ápice del 34 que está endodonciado.

2. Analítica. Valores anormales: VSG, glucosa y ASLO.

3. Análisis histopatológico. Biopsia de la encía adherida: Ampolla subepitelial cuyo techo está constituido por el epitelio, quedando en la base un tejido conjuntivo subepitelial, donde se aprecia un infiltrado inflamatorio crónico inespecífico con algún eosinófilo, pero sin evidencia de acantólisis (Fig. 4).

4. Análisis inmunopatológico. Inmunofluorescencia directa positiva: muestra depósitos de inmunoglobulina G (IgG) y de la fracción C3 del complemento a lo largo de la membrana basal del epitelio.

\section{Diagnóstico:}

Una vez llevados a cabo todos estos pasos en la historia clínica de la paciente llegamos al diagnóstico clínico, histopatológico e inmunopatológico de un penfigoide cicatrizal.

A partir de aquí pedimos el informe al oftalmólogo y 


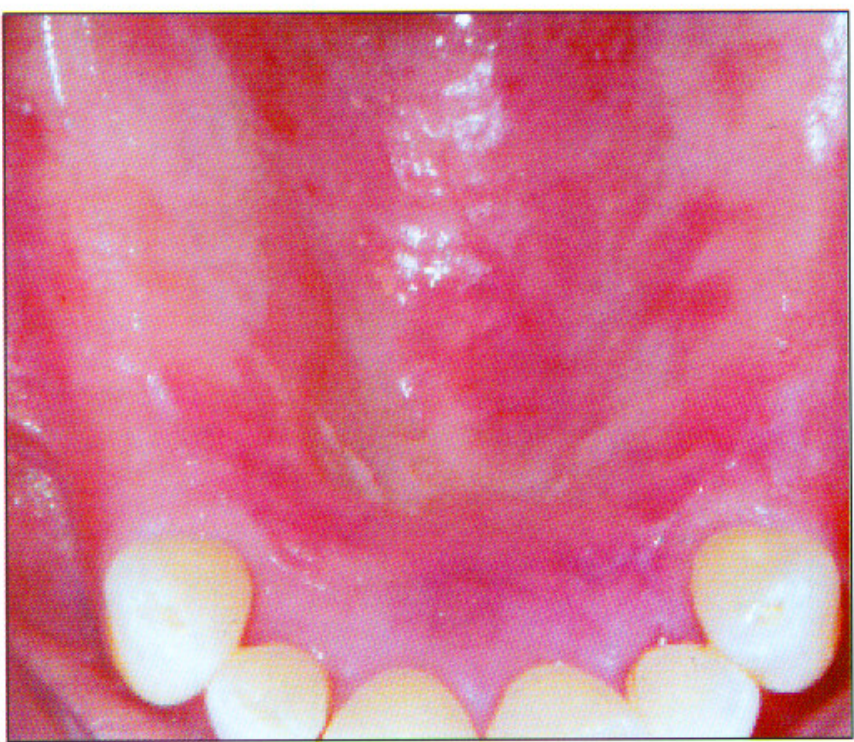

Fig. 5. A los 22 meses del tratamiento.

ginecólogo para descartar la existencia de lesiones en otras mucosas, los cuales no revelaron ninguna anormalidad.

\section{Tratamiento y evolución:}

El tratamiento inicial se basó en un tratamiento con corticoides tópicos (acetónido de Triamcinolona), pero ante la no mejoría de los signos clínicos, se pasó a un tratamiento sistémico con Dapsona (Sulfona).

La dosis de Dapsona se fue amentando poco a poco hasta llegar a $1 \mathrm{~g}$ / día y conforme las lesiones iban mejorando, se disminuía. Sin embargo, a los 6 meses del tratamiento la paciente sufre uno de sus efectos secundarios, anemia, y se suspende. A partir de entonces se vuelve a instaurar una terapia basada únicamente en la aplicación de corticoides tópicos (acetónido de Triamcinolona) junto con técnicas de higiene oral; ajustando la dosis, frecuencia de aplicación y concentración del corticoide según evolucionaba la enfermedad.

Por la localización de las lesiones, para conseguir una mayor efectividad del corticoide tópico, se procedió a la fabricación de unas férulas oclusales que le daban soporte, permitiendo el máximo contacto entre éste y la encía y favoreciendo su aplicación por parte de la paciente. Al mes de esta forma de admi-

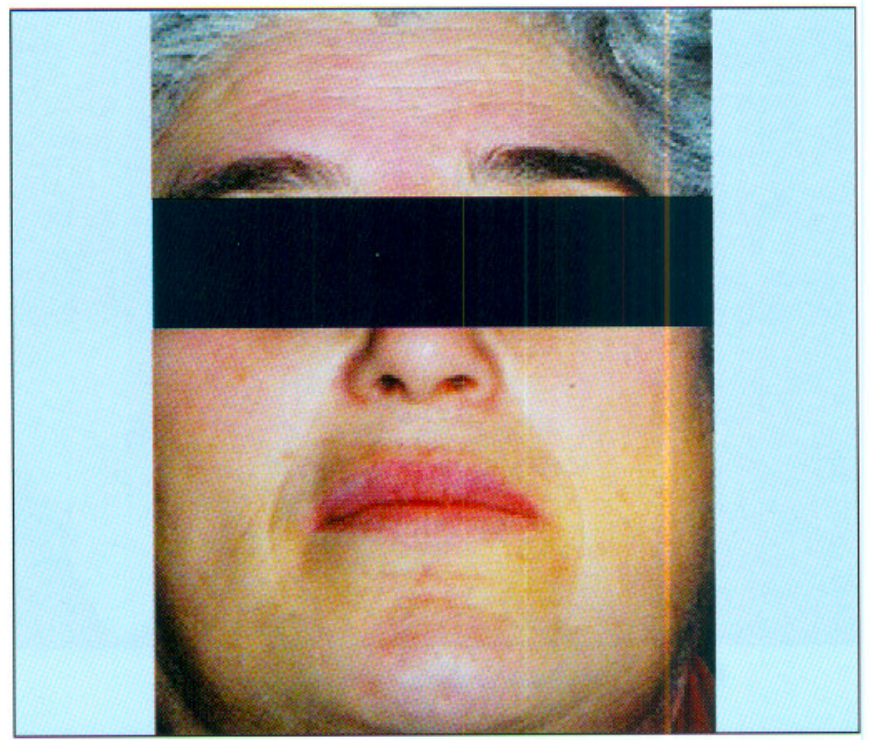

Fig. 6. A los 2 años del tratamiento. Síndrome de Cushing: "Cara de luna llena".

nistración del corticoide la paciente mejora notablemente de su gingivitis descamativa y tres meses después el paladar se vuelve mucho más queratinizado (Fig. 5).

Aunque la aplicación de corticoides tópicos no suele causar problemas a nivel sistémico, a los 2 años del tratamiento, la paciente sufrió un Síndrome de Cushing (Fig. 6), quizás porque la paciente se lo tragaba (obsérvese la "cara de luna llena" con adiposis en cara, cuello y tronco).

Durante visitas posteriores la paciente se encontraba sin cambios, por lo que se le disminuye la concentración del corticoide y se le dice que alterne con periodos de reposo.

Dos años después sufre un nuevo brote en área vestibular del 13 al 23, coincidiendo con una época en la que refiere problemas personales: fallecimiento de su esposo y suegra, hospitalización de su madre...

En el año 2001 aparecen nuevos brotes en encía del 13 al 23 y del 33 al 43 y en paladar duro; además, la paciente relata la aparición de unas molestias en glándulas salivales submandibulares que se encontraban inflamadas. Se le realiza una gammagrafía, no observándose ninguna anormalidad.

En la actualidad las lesiones siguen limitadas a áreas 

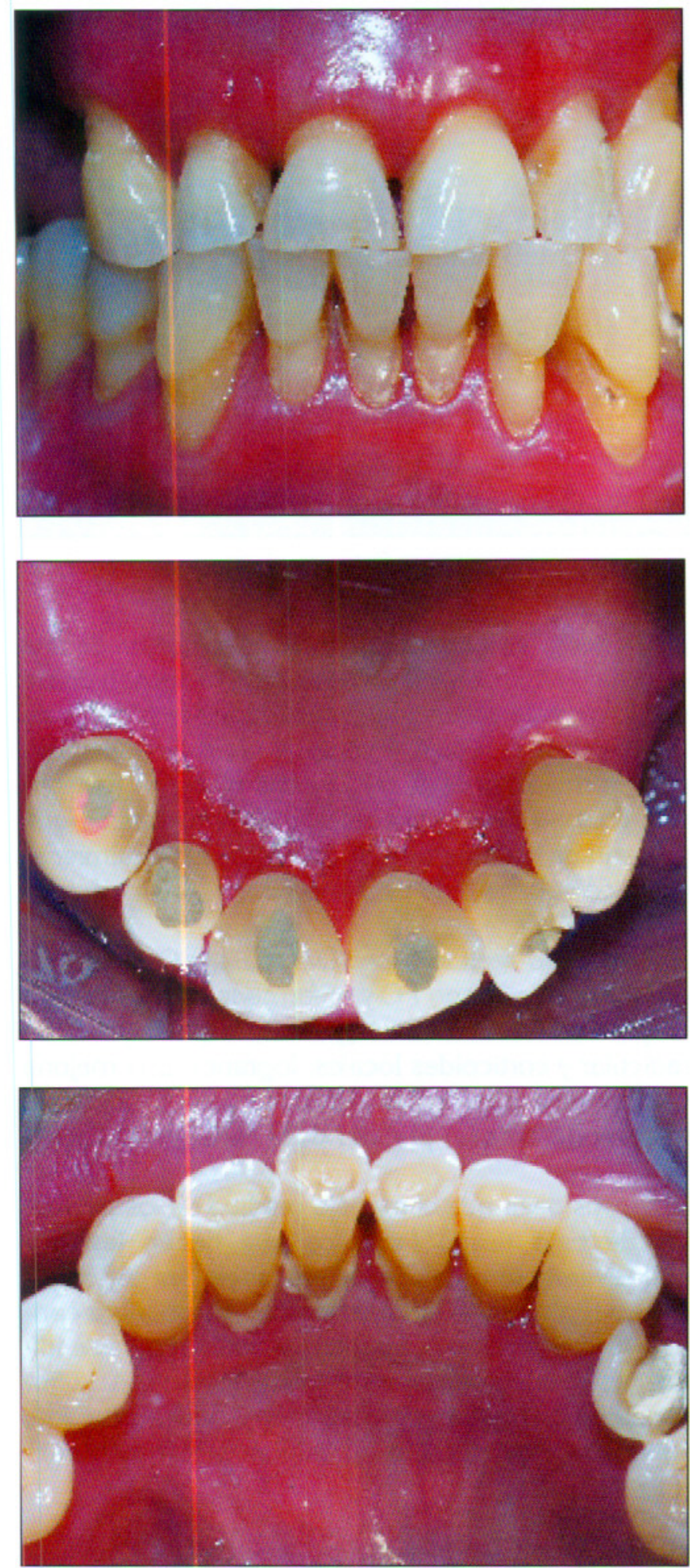

Figs. 7, 8 y 9. Situación actual. Se aprecia ligero eritema en encía, relacionado principalmente con la placa bacteriana.

orales (Figs. 7, 8 y 9), sin extensión a otras mucosas, siendo perfectamente controladas con corticoides tópicos. Para reestablecer su función oral, la paciente requiere un tratamiento protésico. Lo ideal sería la colocación de implantes y realización de una prótesis fija para evitar cualquier apoyo mucoso. Sin embargo esta idea se rechazó de entrada por falta de medios económicos, por lo que hemos decidido la confección de una prótesis mixta donde haremos especial hincapié en que tenga: buen apoyo dentomucoso, perfecto ajuste, buen soporte, estabilidad y retención y que no comprima la mucosa.

Para tratar este tipo de enfermedad siempre tenemos que tener en cuenta la severidad, localización y progresión de las lesiones.

Lo espectacular de este caso clínico ha sido poder llevar a cabo su seguimiento durante tantos años.

\section{DISCUSIÓN}

Como hemos podido observar en este caso clínico, el PC es una enfermedad crónica, con pocos síntomas (problemas de ingesta de determinados alimentos que le son especialmente dolorosos: pan, alimentos ácidos, picantes...) y la evolución, crónica a brotes, suele asociarse a un estado general bueno. En la cavidad oral suele presentarse a nivel de paladar, encías, mucosa yugal, alveolar, mucosa del suelo de la boca y lingual. En estas zonas aparecen lesiones ampollares hemorrágicas de base eritematosa con techo constituido por la totalidad del epitelio $\mathrm{y} / \mathrm{o}$ una gingivitis eritematosa descamativa que suele persistir en el tiempo (en nuestro caso clínico sobre todo en la encía insertada y libre vestibular del 13 al 23), debido a los altos niveles de placa bacteriana que presentan los pacientes ante la dificultad del cepillado. Aunque en la boca no son frecuentes las cicatrices, aparecen en los lugares donde la lesiones se repiten (en nuestro caso en el paladar y encía). Esta curación cicatrizante atrofia la mucosa, pudiendo llegar a producir limitación de la apertura bucal o de la movilidad lingual ${ }^{(2-4)}$.

A pesar de que la afectación de la mucosa oral es la más predominante, y a veces la única, el PC también puede afectar a otras mucosas (ojos, cavidad nasal, faringe, laringe, esófago, genitales y ano) pudiendo 
producir estenosis ${ }^{(9)}$, cosa que no sucedió en nuestro caso. Es por ello que su diagnóstico exige la colaboración de varios especialistas además del odontólogo: oftalmólogos, otorrinolaringólogos, gastroenterólogos..., lo que permitirá su diagnóstico precoz, con un mejor pronóstico y una más alta calidad de cuidados $^{(10 \mathrm{y} 11)}$.

También resulta importante establecer un diagnóstico diferencial con otro tipo de enfermedades vesículo-ampollares: pénfigo vulgar, penfigoide bulloso ${ }^{(12)}$, epidermólisis bullosa adquirida... difícil en muchos casos incluso con el examen histopatológico. En la actualidad para confirmar el diagnóstico de PC se requiere la inmunofluorescencia; no aceptándose la histopatología como criterio de diagnóstico absoluto ${ }^{(1)}$. En el caso de niños, aunque es muy poco frecuente (sólo se han descrito 12 casos en la literatu$\mathrm{ra}^{(13)}$ suele manifestarse únicamente como una gingivitis eritematosa descamativa, por lo que también debemos hacer el diagnóstico diferencial con otro tipo de enfermedades que produzcan este tipo de gingivitis: liquen plano, eritema multiforme, lupus eritematoso discoide...

El tratamiento es crónico e individualizado para cada paciente, ajustando los fármacos y las dosis según su evolución. No existe un agente que sea absolutamente efectivo, aunque la mayoría de las veces suele ser suficiente un tratamiento local con corticoides tópicos de mediana o alta potencia, siempre que las lesiones estén localizadas exclusivamente en piel o en mucosa.

En nuestro caso el tratamiento principal que se está empleando con la paciente es sobre todo local, a base de un corticoide, acetónido de Triamcinolona en contacto con la encía y el paladar. Las concentraciones que se han aplicado han variado a lo largo de los años dependiendo del estado en el que se encontraba la paciente. La dosis y pauta terapéutica se van reduciendo conforme las lesiones se van controlando, con objeto de llegar a la dosis mínima eficaz que mantenga al paciente libre de recaídas; siempre acompañado de técnicas de disminución de placa.

Inicialmente, el tratamiento con dapsona no dio la respuesta esperada y tuvimos que suspenderlo por los efectos secundarios que produjo (anemia).

\section{Tópicos}

Sistémicos

2. DAPSONA: $25-200 \mathrm{mg} / \mathrm{d}$.

3. INMUINOSUPRESORES.

4. CICLOFOSFAMIDA.

5. SULFAMETOXIPIRIDAZINA.

6. ANTIBIÓTICOS: tetraciclina $(1-2 \mathrm{~g} / \mathrm{d})$.

Fig. 10. Fármacos a utilizar en PC oral.

Lisa Cheng y Col. publicaron un caso clínico de una niña de 8 años con PC oral en el que muestran como tratamiento la utilización de aplicaciones tópicas de fluocinolona al $0.05 \% 4$ veces al día más enjuagues con clorhexidina al $0.2 \% 2$ veces al día ${ }^{(13)}$. Refieren una mejoría de los síntomas y signos clínicos que presentaba la paciente, sin embargo, el seguimiento del caso sólo ha sido de 7 meses.

Otro estudio realizado por Damoulis y Col. ${ }^{(14)}$ habla de una paciente con PC y enfermedad periodontal a la que trataron con fase higiénica, raspado y alisado radicular y corticoides locales, logrando una mejoría notable de ambas enfermedades y el control de las mismas durante un periodo de 8 años.

Podemos decir que el manejo médico de los pacientes de bajo riesgo (aquellos que tienen lesiones exclusivamente en mucosa oral) suele ser con corticoides tópicos, y si fracasa; cuando no se logra controlar las lesiones o cuando éstas están muy extendidas, se pueden utilizar corticoides sistémicos, sulfonas, inmunosupresores (azatioprina), ciclofosfamida, sulfametoxipiridazina o antibióticos (tetraciclina) ${ }^{(1)}$ (Fig. 10).

En el año 97 se descubrió un subtipo de PC con anticuerpos antiepiligrina (laminina V). Para su tratamiento, Allbritton y Col describen un caso de una paciente con dicho subtipo de $\mathrm{PC}^{(15)}$, con afectación cutánea, oral y ocular, en el que utilizan una combinación de corticoesteroides sistémicos más ciclo- 
fosfamida, mostrando cómo la paciente mejora inicialmente. Sin embargo, en otro caso clínico de una paciente japonesa de 73 años de edad, con este mismo tipo de PC, Hashimoto et $\mathrm{al}^{(16)}$ señalan que con corticoides e inmunosupresores la paciente mejora de las lesiones cutáneas y mucosas, pero no las oculares, por lo que proponen una combinación de estos dos tratamientos junto con una doble filtración de plasmaféresis para tratar este tipo de PC con afectación ocular. Un tratamiento similar también fue utilizado por Bohn y Col en dos pacientes con PC oral ${ }^{(17)}$, uno de ellos con afectación faríngea. Combinaron transfusiones de plasma con ciclofosfamida observando una remisión de los síntomas y de los brotes de actividad de la enfermedad en 6 y 9 años, sin requerir tratamiento inmunosupresor.

Los últimos estudios sobre el PC giran en torno a la interleuquina-1 (IL-1) y la terapia intravenosa con inmunoglobulina IV (Ig IV) ${ }^{(18)}$. La IL-1 es un importante mediador de la respuesta inflamatoria y juega un papel transcendental en la patogénesis de varias enfermedades autoinmunes.

La tendencia actual de tratamiento en los pacientes considerados de alto riesgo (pacientes con lesiones oculares, nasofaríngeas, esofágicas y/o laríngeas) consiste en infusiones intravenosas de Ig IV, sobre todo cuando el resto de tratamientos sistémicos no resultan efectivos. Sus dosis de aplicación varían de unos autores a otros: Foster y $\mathrm{Col}^{(19)}$ lo utilizan en pacientes que no responden al tratamiento inmunosupresor local o sistémico y que presentan afectación ocular. Utilizan infusiones intravenosas de 2-3 g / $\mathrm{Kg}$ de peso de Ig IV divididas en 3 días, y las repiten en un periodo que oscila de 2 a 6 semanas. Otros autores ${ }^{(20,21)}$ la administran en ciclos de $70 \mathrm{~g}$ diarios durante 4 horas, 3 días consecutivos y aumentan los intervalos entre ciclos conforme mejoran los signos clínicos. Para otros ${ }^{(22)}$, las dosis administradas al paciente deben ser menores, de $1-2 \mathrm{~g} /$ $\mathrm{kg}$ de peso.

Por último cabe señalar que a pesar de los efectos beneficiosos de estos tratamientos, también tienen complicaciones y efectos secundarios considerables. Entre las complicaciones sistémicas que sufrió la paciente debidas al tratamiento podemos desta- car: hipertensión arterial, síndrome de Cushing, anemia e inflamación de las glándulas salivales y fueron porque la paciente lo ingería, ya que es muy difícil que la aplicación tópica tenga efectos a nivel sistémico.

Las complicaciones locales que puede sufrir el paciente con PC principalmente se agravan con el estrés (en el caso de nuestra paciente: muerte de su marido y de su suegra, hospitalización de su madre, obras en su casa); traumatismos orales (roce de los alimentos); prótesis desajustada; incumplimiento del tratamiento y de los períodos de mantenimiento, así como a la falta de higiene oral. Todas ellas tienden a aumentar los períodos de actividad de la enfermedad a nivel oral.

\section{CONCLUSIÓN}

A lo largo de estos 15 años de evolución del PC hemos podido observar que pese a que sea una enfermedad crónica, si el paciente es diagnosticado precozmente y cumple adecuadamente las pautas de tratamiento establecidas, su calidad de vida puede llegar a ser muy aceptable. Es fundamental hacer un diagnóstico diferencial con otras enfermedades vesículo-ampollosas y autoinmunitarias, al igual que revisiones periódicas que aseguren un adecuado control de las lesiones, ajustando las dosis y pautas del tratamiento.

Por todo ello, a la hora de reestablecer la función oral mediante prótesis en este tipo de pacientes, debemos de tener especial cuidado en: el apoyo (preferiblemente dentario para evitar la compresión mucosa), el ajuste (evitar que se traumatice la mucosa) y en que tenga una buena estabilidad, soporte y retención.

\section{AGRADECIMIENTOS}

Nuestro agradecimiento al Dr. Ambrosio Bermejo Fenoll, catedrático de Medicina Bucal de la Facultad de Medicina y Odontología de la Universidad de Murcia, por la aportación iconográfica del caso. 


\section{BIBLIOGRAFÍA}

1. Chan Lawrence S, Razzaque Ahmed A, Anhalt Grant J, Bernauer Wolfgang, Cooper Kevin D, Elder Mark $\mathrm{J}$ et al. The First International Consensus on Mucous Membrane Pemphigoid. Definition, diagnostic Criteria, Pathogenic Factors, Medical Treatment, and Prognostic Indicators. Arch Dermatol 2002; 138: 370-9.

2. Sánchez Pérez A, Bermejo Fenoll A. Penfigoides: manifestaciones orales. En: Bermejo Fenoll A. Medicina Bucal. Madrid: Editorial Síntesis; 1998. p. 186-191.

3. Strassburg M, Knolle G. Mucosa Oral. Atlas a color de enfermedades. $3^{a}$ ed. Madrid: Marban; 1995.

4. Regezi, Sciubba. Patología bucal. Correlación clínico patológica. $3^{a}$ ed. México: McGraw-Hill. Interamericana; 1999.

5. Bean SF. Diagnosis and management of chronic oral mucosal bullous diseases. Dermatol Clin 1987; 5: 751-60.

6. Ahmed AR, Kurgis BS, Rogers IIIRS. Cicatricial pemphigoid. J Am Acad Dermatol 1991; 24: 987-1001.

7. Laskaris G, Sklavounou A, Stratigos J. Bullous pemphigoid, cicatricial pemphigid, and pemphigus vulgaris. Oral Sug Oral Med Oral Pathol 1982; 54: 656-62.

8. Mobini N, Nagaraxalla N, Ahmed AR. Oral pemphigoid. Oral Surg Oral Med Oral Pathol Oral Radiol Endod 1998; 85 : 37-43.

9. Vicent SD, Lilly GE, Baker KA. Clinical, historic, and therapeutic features of cicatricial pemphigoid. Oral Surg Oral Med Oral Pathol 1993; 76: 453-9.

10. Fleming TE, Korman KJ. Cicatricial pemphigoid. J Am Acad Dermatol 2000; 43 (4): 571-91.

11. Ramlogan D, Coulsom IH, McGeorge A.
Cicatricial pemphigoid: a diagnostic problem for the urologist. JR Coll Surg Edinb 2000; 45 (1): 62-3.

12. Banfield CC, Papadavid E, Frith P, Allen J, Wojnarowska FT. Bullous pemphigoid evolving into cicatricial pemphigoid?. Clin Exp Dermatol 1997; 22 (1): 30-3.

13. Lisa Cheng Y, Rees T, Wright J, Plemons J. Childhood oral pemphigoid: a case report and review of the literature. J Oral Pathol Med 2001; 30: 372-7.

14. Damoulis PD, Gagari E. Combined treatment of periodontal disease and benign mucous membrane pemphigoid. Case report with 8 years maintenance. J Periodontol 2000; 71 (10): 16209.

15. Allbritton JI, Nousari HC, Anhalt GJ. Anti-epiligrin (laminin 5) cicatricial pemphigoid. $\mathrm{Br} \mathrm{J}$ Dermatol 1997; 137 (6): 992-6.

16. Hashimoto Y, Suga Y, YoshiiKe T, Hashimoto T, Takamori K. A case of antiepiligrin cicatricial pemphigoid successfully treated by plasmapheresis. Dermatology 2000; 201 (1): 58-60.

17. Bohn J, Jonsson S, Holst R. Successful treatment of recalcitrant cicatricial pemphigoid with a combination of plasma exchange and cyclophosphamide. Br J Dermatol 1999; 141 (3) 53640.

18. Kumari S, Bhol KC, Rehman F, Foster CS, Ahmed AR. Interleukin 1 components in cicatricial pemphigoid. Role in intravenous immunoglobulin therapy. Cytokine 2001; 14 (4): 218-24.

19. Foster CS, Ahmed AR. Intravenous Immunoglobulin therapy for ocular cicatricial pemphigoid: a preliminary study. Ophthalmology 1999; 106 (11): 2136-43.

20. Letko E, Bhol K, Foster SC, Ahmed RA. Influence of intravenous immunoglobulin therapy on serum levels of anti-beta 4 antibodies in ocular cicatricial pemphigoid. A correlation with disease 
activity. A preliminary study. Curr Eye Res 2000; 21 (2): 646-54.

21. Leverkus $M$, Georgi $M$, Nie Z, Hashimoto T, Brocker EB, Zillikens D. Cicatricial pemphigoid with circulating $\lg A$ and $\lg G$ autoantibodies to the central portion of the BP180 ectodomain: beneficial effect of adjuvant therapy with highdose intravenous immunoglobulin. J Am Acad Dermatol 2002; 46 (1): 116-22.

22. Sami N, Bhol KC, Razzaque Ahmed A. Intravenous immunoglobulin therapy in patients with multiple mucosal involvement in mucous membrane pemphigoid. Clin Immunol 2002; 102(1): 59-67.

\section{CORRESPONDENCIA}

María José Moya Villaescusa

C/ García Morato, 16

Santiago de la Ribera

30720 Murcia

e-mail:mjmvillaescusa@hotmail.com 